Ciência e Natura, Santa Maria, v. 37 n. 3 set-dez. 2015, p. 777-795

Revista do Centro de Ciências Naturais e Exatas - UFSM

ISSN impressa: 0100-8307 ISSN on-line: 2179-46017300

\title{
ciênciaenatura
}

\section{As contribuições do Ensino de Ciências para o desenvolvimento cognitivo de alunos nos primeiros anos de escolarização - Estudo de caso comparativo}

\author{
Contributions of Science Teaching for the cognitive development of students in the early years of \\ schooling - Comparative Case Study
}

Janaína P Pretto Carlesso, Luiz Caldeira Brant de Tolentino - Neto, Anaelena Bragança de Moraes

Universidade Federal de Santa Maria

\begin{abstract}
Resumo
O objetivo deste estudo é analisar as correlações entre os níveis do desempenho cognitivo obtidos nas provas operatórias piagetianas e o número de acertos nos testes de ciências, matemática e língua portuguesa obtidos em uma avaliação diagnóstica dos alunos. A amostra foi composta por dois grupos homogêneos sendo que em um deles houve capacitação multidisciplinar do professor regente e intervenções em sala de aula com foco nas ciências. Para o grupo sem intervenções não houve correlação significativa entre os resultados das provas piagetianas e os números de acertos nos três testes. Já para o grupo com intervenções houve correlação positiva significativa entre os níveis de desempenho cognitivo na prova de conservação de líquidos e o número de acertos no teste de matemática. Também houve correlação positiva significativa entre os níveis de desempenho cognitivo na prova de inclusão de classes e o número de acertos em ciências; matemática e em português. Quanto maior o nível de cognição nas provas operatórias maior o número de acertos nos três testes. Pode-se observar através da amostra estudada que houve relação entre os níveis cognitivos e o desempenho dos alunos nas áreas avaliadas. A análise do estudo aponta que o incentivo ao ensino de ciências nos anos iniciais contribui e repercute de forma importante no desenvolvimento cognitivo do aluno.
\end{abstract}

Palavras-chave: cognição; ensino de ciências; avaliação; prova operatória; desempenho.

\begin{abstract}
The objective of this study is to analyze the correlations between cognitive performance levels achieved in operating Piagetian evidence and the number of hits in science, maths and Portuguese obtained on a diagnostic assessment of students. The sample consisted of two homogeneous groups and in one of them there was comprehensively trained teacher and conductor of the interventions in the classroom focusing on sciences. For without intervention group there was no significant correlation between the results of Piagetian evidence and the hit numbers in the three tests. As for the intervention group was no significant positive correlation between cognitive performance levels in fluid preservation of evidence and the number of hits on the math test. There was also a significant positive correlation between cognitive performance levels in the test of inclusion of classes and the number of hits in science; mathematics and Portuguese. The higher the level of cognition in higher operational tests the number of hits in the three tests. It can be observed through the study sample that was no relation between cognitive levels and student performance in the areas evaluated. The study's analysis shows that encouraging science education in the early years contributes and affects significantly to the cognitive development of the student.
\end{abstract}

Keywords: cognition; science education; evaluation; operative test; performance. 


\section{Introdução}

A

$\mathrm{s}$ pesquisas atuais referentes ao incentivo do ensino de ciências nos anos iniciais do ensino fundamental apontam a importância de oportunizar a criança o contato precoce com o universo das ciências nos primeiros anos de escolarização (BIZZO, 2010). Acerca da temática em questão considera-se relevante investir em ciências nessa fase do ciclo escolar, pois a criança está assimilando e construindo suas primeiras concepções sobre objetos, pessoas, conhecimentos, enfim, sobre o mundo em que vive, pois naturalmente mostra-se muito curiosa, exploradora e ativa. $\mathrm{O}$ ensino de ciências pode contribuir para despertar nas crianças a curiosidade e o encantamento pela área científica, cultivando para que o gosto pela ciência se mantenha e frutifique, mais tarde, em jovens interessados em seguir carreiras científicas, o que se constitui numa ação muito significativa (VIECHENESKI E CARLETTO, 2013 apud de UNESCO, 2005).

No Brasil têm sido realizados vários estudos que discutem esse assunto, e muitos deles preocupam-se com a análise de metodologias e materiais para o ensino de Ciências nos anos iniciais, como também para a formação de professores, tais como: Carvalho e Lima (2000); Gouvêa e Leal (2003); Freitas et al. (2004); Lopes et al. (2004), Delizoicov, Lopes e Alves (2005); Delizoicov, (2008); Delizoicov, Angotti e Pernambuco (2009); Brito (2010); Mendonça e Moreira (2012); Viecheneski, Lorenzetti e Carletto
(2012); Viecheneski e Carletto (2013); Dominguez e Trivelato (2014).

Também na literatura é possível encontrar pesquisas que apresentam propostas de intervenções para $\mathrm{O}$ enfrentamento de problemas detectados no ensino de ciências nos anos iniciais, dentre as quais se destacam: DELIZOICOV E ANGOTTI (2000); ROSA (2002); DORZIAT (2004); BATISTA E ARAMAN (2009).

Segundo Fracalanza et al (1986), o ensino de ciências, entre outros aspectos, deve contribuir para o domínio das técnicas de leitura e escrita; permitir o aprendizado dos conceitos básicos das ciências naturais e da aplicação dos princípios aprendidos em situações práticas; possibilitar a compreensão das relações entre a Ciência e a sociedade e dos mecanismos de produção e apropriação dos conhecimentos científicos e tecnológicos; garantir a transmissão e a sistematização dos saberes.

Bizzo (2010) aponta a necessidade do ensino de Ciências favorecer "o desenvolvimento de capacidades que despertem nos estudantes a inquietação diante do desconhecido, buscando explicações lógicas e razoáveis, amparadas em elementos tangíveis". O autor considera ainda, que não se admite mais que o ensino de Ciências se limite a transmitir aos alunos notícias sobre os produtos da Ciência. A Ciência é sim uma postura, uma forma de planejar e coordenar pensamento e ação diante do desconhecido. 
A importância de oportunizar e conduzir o aluno a uma interação com a Ciência dentro de seu cotidiano sociocultural, também é mencionada nos Parâmetros Curriculares Nacionais (PCNs) das séries iniciais do Ensino Fundamental de Ciências, que apresenta como uma de suas funções, proporcionar aos alunos habilidades para utilizar diferentes linguagens para produzir e comunicar suas próprias ideias, bem como, instigar o aluno questionar a realidade, formular problemas e resolvê-los, utilizando, por exemplo, o pensamento lógico, criatividade e intuição (BRASIL, 1997, p.45).

Os PCNs, para o Ensino Fundamental sobre as Ciências Naturais, também ressaltam o uso das Ciências no processo de alfabetização, destacando que desde o início do processo de escolarização e alfabetização, os temas de natureza científica e técnica, por sua presença variada, podem ser de grande ajuda, por permitirem diferentes formas de expressão. Não se trata somente de ensinar a ler e escrever para que os alunos possam aprender Ciências, mas também de fazer usos das Ciências para que os alunos possam aprender a ler e a escrever (BRASIL, 1997, p. 62).

Quando o assunto é relacionado às Ciências, os alunos se aventuram, estabelecendo relações, levantando hipóteses, apresentando argumentações e dando as mais complexas explicações sobre o tema estudado. De acordo com Piaget (1982, p. 138), “a criança reconstrói suas ações e idéias quando se relaciona com novas experiências ambientais. A inteligência é o mecanismo de adaptação do organismo a uma situação nova e, como tal, implica a construção contínua de novas estruturas. Esta adaptação refere-se ao mundo exterior, como toda adaptação biológica".

A partir de tais considerações, este estudo objetiva analisar as correlações entre os níveis de desempenho cognitivo obtidos nas provas operatórias piagetianas e o número de acertos em testes de desempenho em Ciências, Matemática e Língua Portuguesa em uma amostra de alunos de uma escola pública estadual localizada na cidade de Santa Maria, no Estado do Rio Grande do Sul.

\section{Materiais e Métodos}

O tipo de pesquisa realizada nesse estudo é exploratória, classificada como estudo de caso comparativo. $\mathrm{O}$ estudo de caso pode ser realizado com um ou poucos sujeitos, com o objetivo de aprofundar-se e detalhar as características do objeto estudado, sendo utilizada com diferentes propósitos, entre eles a formulação de hipóteses. O método comparativo procede pela investigação de indivíduos, classes, fenômenos ou fatos, com vistas a ressaltar as diferenças e similaridades entre eles (GIL, 2009).

Deve-se esclarecer que não se trata de uma comparação entre grupo controle e amostral. Nestes casos, comuns nas ciências exatas e naturais, o pesquisador busca isolar a(s) variável (is) para mensurar seu(s) impacto(s). Nos estudos comparativos em ciências humanas - como este - procuram-se grupos com características/contextos semelhantes e, ainda assim, as 
peculiaridades inerentes aos grupos humanos são firmemente consideradas.

Primeiramente foi realizado contato com a direção da escola para a apresentação da proposta do estudo. Posteriormente, foi lançado um convite aos professores regentes do $2^{\mathrm{o}}$ ano do ensino fundamental que tivessem disponibilidade e interesse em participar e integrar-se ao trabalho de uma equipe multiprofissional vinculada ao Projeto Observatório da Educação oriunda da Universidade Federal de Santa Maria, RS.

A finalidade da proposta era contribuir pelo período de um ano com a formação multidisciplinar de um professor de escola pública. Para isso o professor deveria participar ativamente na organização dos planejamentos interdisciplinares, semanalmente, na universidade com o auxílio de uma equipe multidisciplinar e aplicá-los em sala de aula.

$\mathrm{O}$ professor interessado que se candidatou a integrar a equipe era regente de uma turma do $2^{\underline{o}}$ ano do ensino fundamental. Sua formação acadêmica era em Letras - Literaturas, especialista em educação ambiental e tinha 35 anos de atuação profissional como docente na rede pública de ensino.

Após a integração do professor na equipe de trabalho, iniciou-se a formação dos grupos para a composição da amostra do estudo e em seguida a coleta de dados, que foi realizada no período de julho de 2012 a julho de 2013.

Por se tratar de um estudo com foco nos anos iniciais do ensino fundamental foram adotados os seguintes critérios de inclusão para a composição da amostra: o aluno deveria estar matriculado, regularmente, no $2^{\mathrm{o}}$ ano do ensino fundamental numa escola pública estadual localizada na cidade de Santa Maria-RS e ter idade de 7 a 9 anos.

Inicialmente, para contemplar os propósitos desta pesquisa, a amostra foi composta por dois grupos - duas turmas de $2^{\circ}$ ano de turnos diferentes (manhã e tarde) em uma mesma escola: Grupo com intervenções (GCI) com 25 alunos, sendo que nesse grupo foram realizadas as atividades interdisciplinares em sala de aula. Este grupo foi regido pela professora participante do projeto Observatório da Educação vinculado à Universidade. O grupo sem intervenções (GSI) foi composto por 24 alunos e manteve as atividades em sala de aula sem qualquer interferência da pesquisa. A professora regente desse grupo não estava vinculada ao projeto e seguiu seus planejamentos habituais.

$O$ fator que diferiu os grupos estudados foi à aplicação das atividades interdisciplinares com enfoque no ensino de ciências.

A formação de um grupo sem intervenções foi relevante, pois através de uma análise comparativa entre os grupos, poderíamos investigar o quanto as atividades interdisciplinares com enfoque no ensino de ciências trabalhadas em sala de aula pelo mesmo professor contribuíram - não isoladamente - no desempenho dos alunos participantes do grupo com intervenções.

Devido a alguns alunos trocarem de escola em ambos os grupos, o número de participantes da amostra passou por alterações. Acerca desse motivo, a amostra definitiva foi composta por 20 alunos no grupo com intervenções (GCI) 
e 18 alunos no grupo sem intervenções (GSI).

A seguir serão apresentadas as etapas do estudo.

\subsection{Questões éticas}

No primeiro momento o professor enviou aos pais/responsáveis pelos alunos o Termo de Consentimento Livre e Esclarecido (TCLE) para viabilizar a autorização da participação do aluno, voluntariamente, na pesquisa. Esse documento visava informar aos participantes, de forma sucinta, sobre os objetivos, os dados dos pesquisadores responsáveis, além de assegurar o sigilo da identidade do aluno. A pesquisadora responsável e seus colaboradores declararam-se comprometidos a zelar pelo cumprimento dos direitos dos sujeitos da pesquisa, garantindo a estes a privacidade e o sigilo de seus dados pessoais e o direito a informação dos resultados obtidos. Este estudo foi aprovado pelo Comitê de Ética e Pesquisa da Universidade Federal de Santa Maria, em seus aspectos éticos e metodológicos de acordo com as Diretrizes estabelecidas na Resolução 196/96 e complementares do Conselho Nacional de Saúde, sob o número do CAEE nº. 20126413.2.0000.5346.

\subsection{Avaliação cognitiva I}

Após o recebimento da autorização dos pais, foi realizada pelo pesquisador responsável a avaliação cognitiva I de todos os alunos que compuseram a amostra. Essa avaliação teve o propósito de verificar se o desempenho cognitivo dos sujeitos participantes dos dois grupos estudados apresentava caráter homogêneo.

Para esta avaliação foi utilizado o método clínico piagetiano.

O método clínico é um procedimento para investigar como as crianças pensam, percebem, agem e sentem que procurando descobrir o que não é evidente no que os sujeitos fazem ou dizem, o que está por trás da aparência de sua conduta, seja em ações ou palavras (DELVAL, 2002, p. 67).

Para a avaliação cognitiva foi utilizado o Kit de Provas Operatórias que é composto de treze provas (embaladas individualmente) em uma caixa de madeira com alça para transporte. O kit contém as seguintes provas: 1. Conservação de pequenos conjuntos discretos de elementos; 2. Conservação da superfície; 3. Conservação de quantidade de líquidos; 4. Conservação de quantidade de matéria; 5. Conservação de peso; 6 . Conservação de volume; 7. Conservação de comprimento; 8. Mudança de critério (dicotomia); 9. Inclusão em classes; 10. Interseção de classes; 11. Seriação de palitos; 12. Combinação de fichas; 13. Predição.

Cabe ressaltar, que o Kit de Provas Operatórias não foi confeccionado pelo pesquisador, o mesmo foi adquirido pronto em uma loja especializada.

No Brasil há alguns estudos realizados que também verificaram através do método clínico o funcionamento dos aspectos cognitivos de alunos provenientes dos anos iniciais do ensino fundamental, tais como: NICÁCIO (2003); BARROS (2006); CAMPOS ET AL (2007); FASSBINDER 
ET AL (2009); SANTOS E OLIVEIRA (2009); MENESTRINA (2011).

O principal critério para a escolha das provas operatórias foi à faixa etária dos alunos (7 a 9 anos de idade).

As provas operatórias selecionadas para avaliação dos alunos neste estudo foram: (1) Conservação de Líquidos, (2) Conservação de Massa, (3) Conjunto Discreto de Elementos, (4) Inclusão de Classes e (5) Seriação de Bastonetes.

A aplicação das provas operatórias foi realizada nas dependências da escola, em uma sala especialmente preparada para tal finalidade, com duração de aproximadamente 30 minutos. Os alunos foram avaliados individualmente pela pesquisadora responsável que tem formação na área de Psicologia.

A avaliação cognitiva de cada aluno foi registrada com uma câmera filmadora, posteriormente foram passadas para um computador e gravadas em DVD para serem analisadas.

O registro das avaliações por meio da filmagem foi relevante para garantir a fidedignidade das informações coletadas, pois foi possível acompanhar detalhadamente o processo que os alunos utilizaram para a construção de suas respostas e para a resolução dos problemas.

$\mathrm{Na}$ análise das avaliações as respostas dos alunos obtidas durante a realização das provas operatórias, foram divididas em três níveis baseados na teoria de Jean Piaget (1975).

$\mathrm{Na}$ tabela 1 é apresentada a classificação do desempenho cognitivo dos alunos nas provas operatórias aplicadas.
Tabela 1 - Classificação dos níveis cognitivos segundo Jean Piaget (1975).

\begin{tabular}{llcc}
\hline $\begin{array}{l}\text { Prova } \\
\text { Operatória }\end{array}$ & Nível I & Nível II & Nível III \\
\hline $\begin{array}{l}\text { Conservação } \\
\text { de Líquidos }\end{array}$ & $\begin{array}{c}\text { Conduta não } \\
\text { conservativa }\end{array}$ & $\begin{array}{c}\text { Conduta } \\
\text { Intermediária }\end{array}$ & $\begin{array}{c}\text { Conduta } \\
\text { conservativa }\end{array}$ \\
$\begin{array}{l}\text { Conservação } \\
\text { de massa }\end{array}$ & $\begin{array}{l}\text { Conduta não } \\
\text { conservativa }\end{array}$ & $\begin{array}{c}\text { Conduta } \\
\text { Intermediária }\end{array}$ & $\begin{array}{c}\text { Conduta } \\
\text { conservativa }\end{array}$ \\
$\begin{array}{l}\text { Conjuntos } \\
\text { discretos de } \\
\text { elementos }\end{array}$ & $\begin{array}{c}\text { Conduta não } \\
\text { conservativa }\end{array}$ & $\begin{array}{c}\text { Conduta } \\
\text { Intermediária }\end{array}$ & $\begin{array}{c}\text { Conduta } \\
\text { conservativa }\end{array}$ \\
$\begin{array}{l}\text { Inclusão de } \\
\text { Classes }\end{array}$ & $\begin{array}{c}\text { Ausência de } \\
\text { quantificação } \\
\text { inclusiva }\end{array}$ & $\begin{array}{c}\text { Contermediária } \\
\text { quantificação }\end{array}$ & $\begin{array}{c}\text { Existência de } \\
\text { inclusiva }\end{array}$ \\
$\begin{array}{l}\text { Seriação de } \\
\text { Bastonetes }\end{array}$ & $\begin{array}{c}\text { Ausência de } \\
\text { seriação }\end{array}$ & $\begin{array}{c}\text { Conduta } \\
\text { Intermediária }\end{array}$ & $\begin{array}{c}\text { Exxito } \\
\text { operatório }\end{array}$ \\
\hline
\end{tabular}

Os níveis das respostas avaliadas correspondem à seguinte graduação: Nível I - respostas e justificativas do aluno não atingem o nível esperado nas questões propostas nas provas operatórias; Nível II - respostas e justificativas do aluno apresentam oscilações/dúvidas nas questões propostas nas provas operatórias; Nível III - respostas e justificativas do aluno atingem o nível esperado nas questões propostas nas provas operatórias.

\subsection{Planejamento e Intervenções Interdisciplinares}

Após a conclusão das avaliações cognitivas I foi iniciada a formação interdisciplinar do professor em encontros semanais na Universidade Federal de Santa Maria (UFSM) com o auxílio de uma equipe multidisciplinar composta por biólogos, licenciados em letras, matemáticos, pedagogos, educadores físicos e psicólogos.

A organização, o planejamento e a aplicação em sala de aula das atividades interdisciplinares envolviam temáticas 
de ciências abrangendo outras áreas do conhecimento, especificamente a matemática e a língua portuguesa. Os planejamentos foram organizados em eixos temáticos inspirados nos Parâmetros Curriculares Nacionais de Ciências Naturais (BRASIL, 1997).

As atividades desenvolvidas nos planejamentos interdisciplinares tiveram os seguintes propósitos: motivar e introduzir os alunos no universo das Ciências, gerando possibilidades de discutir problemas envolvendo fenômenos naturais e as implicações que este conhecimento pode acarretar à sociedade e ao ambiente. Como também incentivar por meio do ensino de Ciências a promoção de estímulos e habilidades em outras áreas do conhecimento (matemática e língua portuguesa).

No trabalho em equipe multidisciplinar foi desenvolvido um amplo leque de atividades articulado com o planejamento escolar do professor.

O planejamento interdisciplinar foi aplicado pelo mesmo professor em sala de aula por dois anos, do $2^{\underline{o}}$ e $3^{\circ}$ ano do ensino fundamental, com o mesmo grupo de alunos.

Durante o $2^{\underline{0}}$ ano (em 2012) o tema das atividades interdisciplinares foi "os animais" e teve os seguintes objetivos: diferenciar os animais vertebrados dos invertebrados; compreender e reconhecer a classificação dos vertebrados; descobrir por meio das atividades e da pesquisa como os animais se alimentam e onde vivem. A partir do tema o professor buscava a conexão entre as áreas do conhecimento nas atividades desenvolvidas em sala de aula.

No quadro 1 é apresentada a síntese dos conteúdos e das atividades que foram trabalhadas em sala de aula pelo professor.

Quadro 1 - Síntese dos conteúdos e atividades desenvolvidas com os alunos no $2^{\underline{0}}$ ano E. F (2012).

\begin{tabular}{|l|l|}
\hline \multicolumn{1}{|c|}{$\begin{array}{c}\text { Temáticas de } \\
\text { Ciências }\end{array}$} & \multicolumn{1}{|c|}{ Atividades } \\
\hline $\begin{array}{l}\text { Animais } \\
\text { vertebrados e } \\
\text { invertebrados; }\end{array}$ & $\begin{array}{l}\text {-Pesquisa em revistas, jornais, } \\
\text { livros e internet; } \\
\text {-Elaboração de cartazes; } \\
\text {-Leitura e interpretação de } \\
\text { textos; }\end{array}$ \\
Animais \\
$\begin{array}{l}\text {-Elaboração de um álbum } \\
\text { vertebrados - cinco } \\
\text { classes: mamíferos, } \\
\text { aves, répteis, } \\
\text { anfíbios e peixes. } \\
\text { Animais selvagens; } \\
\text {-Experimento: Construção de } \\
\text { um terrário; } \\
\text {-Confecção de fichas com } \\
\text { características dos animais; } \\
\text {-Atividade lúdica - Jogo de } \\
\text { Dominó; } \\
\text { animais de acordo } \\
\text { com a alimentação - } \\
\text { carnívoros, herbívor } \\
\text { os, onívoros. }\end{array}$ \\
$\begin{array}{l}\text {-Apresentação oral de } \\
\text { trabalhos sobre os animais e } \\
\text { discussão sobre a temática. } \\
\text { Enquete - escolha da temática } \\
\text { desenvolvida no 3o ano (E.F) }\end{array}$ \\
\end{tabular}

Para que a equipe pudesse organizar as atividades que seriam aplicadas no $3^{\text {o }}$ ano do ensino fundamental (em 2013), foi elaborada uma enquete com a finalidade de investigar quais temas os alunos tinham interesse de estudar no próximo ano.

A temática escolhida pelos alunos foi "o ciclo da água". A partir desse resultado a equipe multidisciplinar - da qual a professora faz parte - passou a organizar as atividades do planejamento interdisciplinar do $3^{\text {o }}$ ano em torno do tema manifestado pelos alunos. A aplicação do planejamento continuou 
sendo realizada pelo mesmo professor e com os mesmos alunos.

No quadro 2 é mostrada a síntese dos conteúdos e das atividades que foram trabalhadas em sala de aula no $3^{\circ}$ ano.

Quadro 2 - Síntese dos conteúdos e atividades desenvolvidas com os alunos no $3^{\underline{0}}$ ano E.F (2013).

\begin{tabular}{|c|c|}
\hline $\begin{array}{c}\text { Temáticas de } \\
\text { Ciências }\end{array}$ & Atividades \\
\hline $\begin{array}{l}\text { Ciclo da água; } \\
\text {-tipos de poluição; } \\
\text { Poluição do ar } \\
\text { - os efeitos no } \\
\text { ambiente e na } \\
\text { saúde; }\end{array}$ & $\begin{array}{l}\text {-Pesquisa em revistas, jornais, } \\
\text { livros e internet, elaboração de } \\
\text { cartazes, leitura e } \\
\text { interpretação de textos sobre } \\
\text { poluição; } \\
\text {-Vídeos sobre o ciclo da água; } \\
\text { tipos de poluição; poluição de } \\
\text { solos; } \\
\text { - Músicas: "Se você pensa"; } \\
\text { "Rap da Poluição"; "Nossa } \\
\text { Turma”; } \\
\text { - Poesia - "A evaporação } \\
\text { purifica a água"; } \\
\text {-Questionário sobre a } \\
\text { utilização da água em casa; } \\
\text {-Dinâmica em grupo: } \\
\text { "Percepção de sons”; } \\
\text {-Construção de um kit de } \\
\text { Ciências; } \\
\text {-Construção de pluviômetro; } \\
\text {-Confecção de um marcador } \\
\text { de página "SOS SALVE } \\
\text { NOSSO PLANETA"; } \\
\text { - “Enterrando coisas no solo" } \\
\text { - Texto: “O perfil do solo" } \\
\text {-Coleta e análise de solos; }\end{array}$ \\
\hline
\end{tabular}

As aulas desenvolvidas do $2^{\underline{o}}$ ao $3^{\underline{0}}$ ano foram, em geral, desenvolvidas em momentos de explicação (através da aula expositiva), de realização de atividades práticas, de orientação e discussão com os alunos e correção das atividades propostas.

Priorizaram-se atividades que incentivassem o pensamento e o senso crítico dos alunos: discussões em grupo, vídeos, experiências, trabalhos coletivos, textos para a leitura, interpretação e debate.

Após a conclusão das atividades e para identificar os reflexos da interdisciplinaridade, foi realizada a avaliação do desempenho dos alunos dos dois grupos estudados.

\subsection{Avaliação do desempenho}

Para avaliar o desempenho dos estudantes, houve uma busca por um instrumento bem elaborado, consagrado no sentido de ter várias edições e que incluísse Ciências. Optou-se pela "Avaliação Diagnóstica" originária do Programa Avalia-BH.

O Avalia-BH é um programa de avaliação do Ensino Fundamental da Rede Municipal de Educação de Belo Horizonte, que oferece uma medida do desempenho escolar por meio de testes de Ciências da Natureza, Língua Portuguesa e Matemática. Seu objetivo é avaliar, anualmente, os estudantes do $3^{\underline{0}}$ ao $9^{-}$ano do Ensino Fundamental das escolas da Prefeitura, bem como identificar os fatores que interferem no desempenho dos estudantes. Ressalta-se que a Secretaria Municipal de Educação de Belo Horizonte participa, ainda, das avaliações sistêmicas e/ou diagnósticas em nível federal (Prova Brasil e Provinha Brasil), além de os Proeb (Proalfa e Simave), em nível estadual (DIAS E SILVA, 2011).

Os testes do Avalia-BH verificam se o aluno já desenvolveu a capacidade de mobilizar conhecimentos e informações para resolver questões relacionadas à compreensão de textos, no teste de Língua Portuguesa, e situações- 
problema, no teste de Matemática. No teste das Ciências da Natureza avalia-se se o aluno desenvolveu a capacidade de levantar hipóteses sobre os fenômenos químicos e físicos, sobre os seres vivos e sobre a relação entre o homem e a natureza e entre o homem e a tecnologia (RIBEIRO, 2012).

Para a avaliação do desempenho dos alunos deste estudo foram utilizados os testes de Ciências da Natureza, Matemática e Língua Portuguesa aplicados na edição do $1^{\mathrm{o}}$ semestre de 2013 do Programa Avalia-BH.

A avaliação do desempenho da amostra estudada foi realizada em sala de aula de forma individual em um espaço coletivo.

Os testes foram aplicados pelo pesquisador e seus colaboradores em dois dias nos turnos da manhã e tarde. Cabe ressaltar, que durante a aplicação dos testes foi realizado um intervalo na hora do recreio.

As professoras regentes das turmas estavam presentes durante a realização dos testes.

A leitura do enunciado de cada questão foi feita em voz alta por um dos aplicadores. Caso os alunos tivessem dúvidas deveriam levantar a mão que o aplicador iria atendê-los em suas classes.

O caderno de testes era composto de questões 1 a 24 (ciências); 25 a 48 (matemática) e 49 a 72 (português). Sendo que a primeira folha tinha um espaço destinado para o preenchimento pelo aluno de seus dados de identificação.

A ordem da aplicação dos testes foi: $1^{\circ}$ Questões de Ciências, 2o Questões de

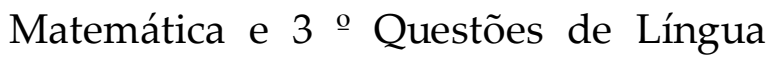
Portuguesa.
No primeiro dia os alunos realizaram os testes demorando em média quatro horas para finalizar as questões. No segundo dia os alunos levaram cerca de quase três horas.

Observou-se durante a aplicação dos testes nas duas turmas, que alguns alunos não seguiam a ordem em que era feita a leitura do teste pelos aplicadores, pois terminavam antes e não conseguiam esperar, desta forma seguiam fazendo o teste, lendo as questões sozinhos.

No primeiro dia os alunos dos dois grupos de forma geral, mostraram-se ansiosos.

Os alunos do grupo coordenado pela professora integrante do projeto Observatório da Educação, em alguns momentos faziam questionamentos em relação a "significado de palavras" que estavam presente nas questões dos testes, como exemplo: fósseis, armazenamento e recursos.

Já os alunos do outro grupo fizeram perguntas à professora referente ao entendimento de algumas questões durante a realização dos testes de Ciências e Matemática.

No segundo dia, os alunos de forma geral, mostraram-se mais calmos para responder as questões do teste de Língua Portuguesa.

A correção do número de acertos nos testes foi quantificada conforme a classificação apresentada no quadro 3 .

\subsection{Avaliação cognitiva II}

Novamente após período de um ano foi realizada, pelo mesmo examinador (pesquisador responsável), a avaliação cognitiva dos alunos dos dois grupos do 
estudo, sendo utilizado o mesmo método e a aplicação das mesmas provas operatórias piagetianas utilizadas na avaliação cognitiva I.

Após o encerramento das etapas previstas neste estudo, os resultados do acompanhamento realizado com os alunos foram entregues em forma de relatório para a direção da escola e também para os pais/ou responsáveis.

No documento redigido para a escola constava o desempenho geral das duas turmas avaliadas. $\mathrm{O}$ parecer individual, elaborado para cada aluno, foi entregue aos pais/responsáveis sob forma de relatório.

\section{Construção das variáveis}

O desempenho cognitivo foi avaliado por meio das respostas dos alunos durante a aplicação das provas operatórias.

Para a avaliação, as respostas foram divididas, novamente, nos três níveis descritos por Piaget (tabela 1).

O desempenho escolar nas três áreas avaliadas (ciências, matemática e língua portuguesa) foi quantificado e classificado conforme o número de acertos nos testes.

No quadro 3 pode-se observar tal classificação:
Quadro 3 - Classificação do desempenho dos alunos

\begin{tabular}{|c|l|}
\hline $\begin{array}{c}\text { Classificação do } \\
\text { Desempenho } \\
\text { (No de acertos) }\end{array}$ & \multicolumn{1}{|c|}{ Caracterização } \\
\hline $\begin{array}{c}\text { Insatisfatório } \\
\text { (0 a 9) }\end{array}$ & $\begin{array}{l}\text { Alunos que apresentam esse } \\
\text { desempenho revelam estar em } \\
\text { processo de aquisição inicial de } \\
\text { competências e habilidades para } \\
\text { o período de escolarização onde } \\
\text { se encontram. }\end{array}$ \\
\hline $\begin{array}{c}\text { Intermediário } \\
\text { (10 a 17) }\end{array}$ & $\begin{array}{l}\text { Alunos que apresentam esse } \\
\text { desempenho apresentam } \\
\text { habilidades básicas e essenciais } \\
\text { ao período de escolarização que } \\
\text { se encontram, necessitando de } \\
\text { mais esforços para atingir } \\
\text { habilidades mais elaboradas; }\end{array}$ \\
\hline Satisfatório & $\begin{array}{l}\text { Alunos que apresentam esse } \\
\text { desempenho revelam ser } \\
\text { capazes de atingir as habilidades } \\
\text { previstas para a série como } \\
\text { também há possibilidade de } \\
\text { desenvolver habilidades que } \\
\text { superam aquelas esperadas no } \\
\text { período de escolaridade que se } \\
\text { encontram. }\end{array}$ \\
\hline
\end{tabular}

A normalidade do número de acertos em Ciências, matemática e língua portuguesa foi avaliada estatisticamente por meio do teste de Shapiro-Wilk.

Como, os resultados para as três variáveis testadas foram de não normalidade, foi utilizado o teste nãoparamétrico U de Mann-Whitney para comparar o desempenho cognitivo entre os dois grupos (com intervenções e sem intervenções).

Para avaliar a correlação entre os níveis do desempenho cognitivo nas provas operatórias de conservação, classificação e seriação e o número de acertos nas três provas foi utilizando o coeficiente de correlação nãoparamétrico de Spearman. 
Em todos os testes estatísticos admitiu-se o nível de significância estatística de $5 \%$.

A análise estatística foi realizada utilizando-se o aplicativo computacional STATISTICA (versão 9.1) desenvolvido pela StatSoft SOUTH AMERICA.

\section{Resultados}

A partir dos resultados obtidos na avaliação cognitiva I dos alunos, foi analisado se os grupos com e sem intervenções eram comparáveis.

Nas tabelas 2 e 3 podem-se observar as frequências nos níveis do desempenho cognitivo dos alunos em cada prova operatória. Também são apresentados os resultados do teste estatístico.

Conforme a tabela 2, não houve diferença significativa $(p>0,05)$ entre $o$ grupo sem intervenções e o com intervenções em todas as provas operatórias piagetianas realizadas na avaliação cognitiva I, indicando que os grupos são comparáveis.

$\mathrm{Na}$ análise dos dados obtidos na avaliação cognitiva II, ou seja, após o encerramento das atividades interdisciplinares em sala de aula, novamente foi verificado se os grupos com e sem intervenções eram comparáveis (tabela 3).

Observa-se novamente na tabela 3, que não houve diferença significativa $(p>0,05)$ entre o grupo sem intervenções e o grupo com intervenções em todas as provas operatórias.

Portanto, os alunos participantes dos dois grupos do estudo apresentaram desempenho cognitivo com caráter semelhante, nesta avaliação. 
Tabela 2 - Frequência e comparação entre os níveis de desempenho cognitivo nas provas operatórias piagetianas na avaliação cognitva I dos grupos sem intervenções GSI (n=24) e com intervenções GCI (n= 25) de alunos do ensino fundamental de uma escola pública na cidade de Santa Maria, RS, (2013).

\begin{tabular}{|c|c|c|c|c|c|c|c|}
\hline \multirow[b]{2}{*}{$\begin{array}{l}\text { Prova } \\
\text { Operatória }\end{array}$} & \multicolumn{3}{|c|}{$\begin{array}{c}\text { Grupo sem intervenções } \\
\text { GSI } \\
\end{array}$} & \multicolumn{3}{|c|}{$\begin{array}{c}\text { Grupo com intervenções } \\
\text { GCI }\end{array}$} & \multirow[b]{2}{*}{$\begin{array}{c}\mathrm{p}- \\
\text { valor }\end{array}$} \\
\hline & I (\%) & II (\%) & III (\%) & I (\%) & II (\%) & III (\%) & \\
\hline Líquidos & $15(83,3)$ & $2(11,1)$ & $0(0,0)$ & $15(75,0)$ & $2(10,0)$ & $3(15,0)$ & 0,776 \\
\hline Massa & $16(88,9)$ & $2(11,1)$ & $0(0,0)$ & $15(75,0)$ & $4(20,0)$ & $1(5,00)$ & 0,623 \\
\hline $\begin{array}{l}\text { Inclusão } \\
\text { de Classes }\end{array}$ & $1(5,56)$ & $2(11,1)$ & $15(83,3)$ & $1(5,00)$ & $3(15,0)$ & $16(80,0)$ & 0,265 \\
\hline $\begin{array}{l}\text { Conjuntos } \\
\text { discretos }\end{array}$ & $1(5,56)$ & $6(33,3)$ & $11(61,1)$ & $1(5,00)$ & $6(30,0)$ & $13(65,0)$ & 0,461 \\
\hline Seriação & $2(11,1)$ & $7(38,9)$ & $9(50,0)$ & $1(5,00)$ & $6(30,0)$ & $13(65,0)$ & 0,916 \\
\hline
\end{tabular}

* Significância do teste não paramétrico U de Mann-Whitney.

Tabela 3 - Frequência e comparação entre os níveis de desempenho cognitivo nas provas operatórias piagetianas na avaliação cognitiva II dos grupos sem intervenções GSI ( $n=24)$ e com intervenções GCI ( $n=$ 25) de alunos do ensino fundamental de uma escola pública na cidade de Santa Maria, RS, (2013).

\begin{tabular}{|c|c|c|c|c|c|c|c|}
\hline \multirow[b]{2}{*}{$\begin{array}{l}\text { Prova } \\
\text { Operatória }\end{array}$} & \multicolumn{3}{|c|}{$\begin{array}{c}\text { Grupo sem intervenções } \\
\text { GSI } \\
\end{array}$} & \multicolumn{3}{|c|}{$\begin{array}{c}\text { Grupo com intervenções } \\
\text { GCI }\end{array}$} & \multirow[b]{2}{*}{$\begin{array}{c}\text { p- } \\
\text { valor }\end{array}$} \\
\hline & $\mathrm{I}(\%)$ & II (\%) & III (\%) & $\mathrm{I}(\%)$ & II (\%) & III (\%) & \\
\hline Líquidos & $6(33,3)$ & $1(5,56)$ & $11(61,1)$ & $6(33,3)$ & $3(15,0)$ & $11(55,0)$ & 0,868 \\
\hline Massa & $5(27,7))$ & $3(16,6)$ & $10(55,5)$ & $4(20,0)$ & $7(35,0)$ & $9(45,0)$ & 0,811 \\
\hline $\begin{array}{l}\text { Inclusão } \\
\text { de Classes }\end{array}$ & $0(0,0)$ & $2(11,1)$ & $16(88,9)$ & $1(5,00)$ & $1(5,00)$ & $18(90,0)$ & 0,956 \\
\hline $\begin{array}{l}\text { Conjuntos } \\
\text { discretos }\end{array}$ & $0(0,0)$ & $6(33,3)$ & $12(66,6)$ & $2(10,0)$ & $1(5,00)$ & $17(85,0)$ & 0,287 \\
\hline Seriação & $1(5,56)$ & $2(11,1)$ & $15(83,3)$ & $1(5,00)$ & $0(00,0)$ & $19(95,0)$ & 0,272 \\
\hline
\end{tabular}

$\mathrm{Na}$ tabela 4 são apresentadas as correlações entre os níveis de desempenho cognitivo nas provas operatórias de conservação, classificação e seriação obtidas na etapa de avaliação cognitiva II e as faixas do desempenho escolar em ciências, matemática e língua portuguesa nos grupos sem intervenções e com intervenções em sala de aula. 
Tabela 4 - Valores dos coeficientes de correlação de Spearman e significância entre os níveis de desempenho cognitivo nas provas piagetianas e os números de acertos nos testes de desempenho em uma amostra sem intervenções $(n=18)$ e amostra com intervenções $(n=20)$ de alunos do ensino fundamental de uma escola pública na cidade de Santa Maria, RS, (2013).

\begin{tabular}{|c|c|c|c|c|}
\hline & $\begin{array}{r}\text { Grupo sem } \\
\text { intervenções } \\
\text { GSI }\end{array}$ & & $\begin{array}{l}\text { po com } \\
\text { venções } \\
\text { GCI }\end{array}$ & \\
\hline Variáveis & $\mathbf{r}_{\mathrm{s}}$ & $\begin{array}{l}\text { p- } \\
\text { valor }\end{array}$ & $\mathbf{r s}_{\mathrm{s}}$ & $\begin{array}{l}\text { p- } \\
\text { valor }\end{array}$ \\
\hline $\begin{array}{l}\text { Prova operatória de Conservação de Líquidos } x \\
\text { Número de acertos no teste de ciências }\end{array}$ & 0,330 & 0,196 & 0,287 & 0,246 \\
\hline $\begin{array}{l}\text { Prova operatória de Conservação de Líquidos x } \\
\text { Número de acertos no teste de matemática }\end{array}$ & $-0,131$ & 0,613 & 0,576 & 0,012 \\
\hline $\begin{array}{l}\text { Prova operatória de Conservação de Líquidos } \mathrm{x} \\
\text { Número de acertos no teste de português }\end{array}$ & $-0,114$ & 0,722 & 0,381 & 0,118 \\
\hline $\begin{array}{l}\text { Prova operatória de Conservação de massa } x \\
\text { Número de acertos no teste de ciências }\end{array}$ & $-0,031$ & 0,903 & 0,362 & 0,138 \\
\hline $\begin{array}{l}\text { Prova operatória de Conservação de massa } x \\
\text { Número de acertos no teste de matemática }\end{array}$ & 0,076 & 0,769 & 0,464 & 0,052 \\
\hline $\begin{array}{l}\text { Prova operatória de Conservação de massa } x \\
\text { Número de acertos no teste de português }\end{array}$ & $-1,260$ & 0,236 & 0,348 & 0,156 \\
\hline $\begin{array}{l}\text { Prova operatória de Inclusão de Classes } x \\
\text { Número de acertos no teste de ciências }\end{array}$ & 0,322 & 0,206 & 0,555 & 0,016 \\
\hline $\begin{array}{l}\text { Prova operatória de Inclusão de Classes x } \\
\text { Número de acertos no teste de matemática }\end{array}$ & 0,318 & 0,213 & 0,535 & 0,022 \\
\hline $\begin{array}{l}\text { Prova operatória de Inclusão de Classes } x \\
\text { Número de acertos no teste de português }\end{array}$ & 0,294 & 0,352 & 0,517 & 0,027 \\
\hline $\begin{array}{l}\text { Prova operatória de Conjuntos discretos de } \\
\text { elementos x Número de acertos no teste de ciências }\end{array}$ & 0,012 & 0,961 & 0,336 & 0,171 \\
\hline $\begin{array}{l}\text { Prova operatória de Conjuntos discretos de } \\
\text { elementos x Número de acertos no teste de } \\
\text { matemática }\end{array}$ & 0,176 & 0,497 & 0,379 & 0,119 \\
\hline $\begin{array}{l}\text { Prova operatória de Conjuntos discretos de } \\
\text { elementos x Número de acertos no teste de português }\end{array}$ & 0,130 & 0,685 & 0,318 & 0,197 \\
\hline $\begin{array}{l}\text { Prova operatória de Seriação de bastonetes } x \\
\text { Número de acertos no teste de ciências }\end{array}$ & 0,246 & 0,339 & 0,404 & 0,095 \\
\hline $\begin{array}{l}\text { Prova operatória de Seriação de bastonetes } x \\
\text { Número de acertos no teste de matemática }\end{array}$ & 0,149 & 0,566 & 0,401 & 0,098 \\
\hline $\begin{array}{l}\text { Prova operatória de Seriação de bastonetes } x \\
\text { Número de acertos no teste de português }\end{array}$ & 0,279 & 0,378 & 0,399 & 0,100 \\
\hline
\end{tabular}

$\mathrm{r}_{\mathrm{s}}=$ Coeficiente de correlação de Spearman; * significância estatística $(\mathrm{p} \leq 0,05)$

\section{Discussão}

Para o grupo sem intervenções (GSI) em sala de aula não houve correlação significativa entre os resultados das provas operatórias piagetianas e os números de acertos nos três testes (Ciências, Matemática e Língua Portuguesa).

Para o grupo com intervenções interdisciplinares (GCI) houve correlação positiva significativa entre os níveis de desempenho cognitivo na prova de conservação de líquidos e o número de acertos no teste de matemática. Quanto maior o nível de cognição nesta prova operatória maior o número de acertos em matemática.

Também houve correlação positiva significativa entre os níveis de desempenho cognitivo na prova de inclusão de classes e o número de acertos em ciências; número de acertos em matemática e número de acertos em português. Quanto maior o nível de 
cognição nas provas operatórias maior o número de acertos nos três testes. Podese observar que embora o resultado não tenha sido significativo, este foi próximo da significância estatística $\quad(p=0,052)$ para os níveis de desempenho cognitivo na prova de conservação de massa e o número de acertos no teste de matemática. Quanto maior o nível de cognição nesta prova maior o número de acertos em matemática.

Neste estudo foram encontrados resultados estatisticamente importantes, pois para o grupo com intervenções interdisciplinares quanto maior o nível de cognição nas provas operatórias piagetianas maior o número de acertos nos três testes avaliados (tabela 3).

No entanto, os resultados demonstraram que houve correlação entre os aspectos cognitivos e desempenho satisfatório nas três áreas avaliadas. Observa-se que a hipótese do estudo foi confirmada. Além dos resultados referentes ao desempenho dos alunos, pode-se verificar que a proposta de trabalho desenvolvida pelo projeto Observatório da Educação também promoveu contribuições relevantes para a ampliação da prática do professor através do incentivo de práticas interdisciplinares com enfoque em temáticas de Ciências.

Verificou-se que o ensino de ciências nos anos iniciais favorece não apenas a ampliação do repertório de conhecimentos das crianças, mas auxilia a desenvolverem habilidades e valores que lhes possibilitam continuar aprendendo, atingindo patamares mais elevados de cognição (LIMA; MAUÉS, 2006).
Nesse sentido, a ciências contribuem de forma importante para o desenvolvimento intelectual das crianças, pois “[...] está relacionada à qualidade de todas as aprendizagens, contribuindo para desenvolver competências e habilidades que favorecem a construção do conhecimento em outras áreas" (UNESCO, 2005, p. 4).

Segundo Ferracioli (1999), Piaget aponta que o desenvolvimento mental do indivíduo começa desde o nascimento até a idade adulta é um processo contínuo de construção de estruturas variáveis, que, ao lado de características que são constantes e comuns a todas as idades, refletem o seu grau de desenvolvimento intelectual.

Para Piaget (1967), estruturas variáveis são maneiras de organização das atividades mentais, que englobam os aspectos motor ou intelectual e afetivo, tanto na dimensão individual como na social.

\section{Conclusão}

Atribuir o ganho de desempenho a intervenção interdisciplinar com temas de ciências é tão temeroso quanto necessário neste estudo de caso comparativo. Deve-se ter atenção às particularidades das turmas e dos indivíduos que delas fazem parte, sem ignorar que em hipótese alguma se consegue controlar todas as variáveis como nos testes empíricos das ciências exatas: é impossível isolar apenas a variável em estudo, quando o campo de pesquisa é uma escola e o objeto, o conhecimento. 
Contudo, a robustez dos dados estatísticos apresentados contribui, em outra esfera, com a discussão.

A análise do estudo apontou que o incentivo ao ensino de ciências nos anos iniciais por meio da aplicação de uma proposta interdisciplinar de longo prazo, contribuiu de forma importante para o desenvolvimento cognitivo dos alunos não somente em ciências, mas também em língua portuguesa e na matemática. Tal argumento corrobora a importância de utilizar no planejamento e implementação do ensino estratégias que incorporem o emprego de práticas interdisciplinares.

No entanto, para alcançarmos a esses resultados, foi necessário investir na formação do professor, que organizou seus planejamentos escolares com o auxílio de uma equipe multidisciplinar - que também ganhou, capacitou-se, com os estudos e com a experiência da professora. De forma geral, a proposta desenvolvida nesse estudo foi relevante para todos os envolvidos nesse processo. Acerca disso, cabe ressaltar que o desafio da implementação de uma prática interdisciplinar, exige esforço coletivo. Nessa perspectiva, observa-se que o apoio e a orientação da equipe foram relevantes para potencializar o trabalho do professor em sala de aula e também incentivar o cultivo da postura cientifica nos alunos.

Portanto, para que o ensino promova significados importantes para $\mathrm{O}$ desenvolvimento cognitivo dos alunos, sugere-se aos professores dos anos iniciais do ensino fundamental que invistam em projetos temáticos com enfoque no ensino de Ciências propostas de trabalho que façam a integração com outras áreas de conhecimento. Acredita-se, que por meio da implantação de projetos com enfoque na interdisciplinaridade no âmbito escolar, muitos benefícios podem ser alcançados de forma ampla tanto para alunos como para professores.

\section{Agradecimentos}

Agradecimentos aos revisores, colaboradores, e CAPES pelo financiamento desta pesquisa.

\section{Referências}

BATISTA, I.L.; ARAMAN, E.M.O. Uma abordagem histórico-pedagógica para o ensino de Ciências nas séries iniciais do Ensino Fundamental. Revista Electrónica de Enseñanza de las Ciencias, v. 8, n. 2, 2009. Disponível em: $<$ http://reec.uvigo.es/volumenes/volume n8/ART5 Vol8 N2.pdf > Acesso em: 29 de abr. de 2015.

BARROS, C.E. Noções de conservação, seriação e classificação em escolares com dislexia do desenvolvimento. 2006 Dissertação (Mestrado em Ciências Médicas) Universidade Estadual de Campinas, Campinas - SP, 2006.

BIZZO, N. Ciências Fácil ou Difícil? São Paulo: Ed. Biruta, 2010.

BRASIL. Secretaria de Educação Fundamental. Parâmetros curriculares nacionais: Ciências naturais. Brasília: MEC/SEF, 1997. 
BRITO, N.S.Q. A Biologia e a História da disciplina ensino de Ciências nos currículos do curso de Pedagogia da UFSC (1960 - 1990). 2010. Tese (Doutorado) - Universidade Federal de Santa Catarina, Florianópolis, 2010.

CAMPOS, L.G.A. et aL. Caracterização do desempenho de crianças com transtorno de déficit de atenção e hiperatividade (TDAH) em provas operatórias: estudos de casos. Revista de Psicopedagogia,v.24, n.75, pp. 218-228, 2007. Disponível em: < http://pepsic.bvsalud.org/scielo.php?pid $=$ S0103-

$\underline{84862007000300002 \& \text { script }=\text { sci arttext }>}$ Acesso em: 29 de abr. de 2015.

CARVALHO, A.M.P; LIMA, M.C.B. Exercício de raciocínio em três linguagens: ensino de Física nas Séries Iniciais. In: ENCONTRO DE PESQUISA EM ENSINO DE FÍSICA, 7. Programas e Resumos... Florianópolis: SBF, 2000.

DELIZOICOV, D; ANGOTTI, J.A; PERNAMBUCO, M.M. Ensino de Ciências: fundamentos e métodos. 3. ed. São Paulo: Cortez, 2009.

DELIZOICOV, N.C. Educação em Ciência e cidadania: o professor do ensino fundamental - anos iniciais. In: Seminário de Pesquisa em Educação da região sul - anped-sul, 7. [CD-ROM]; 2008; Brasil, p. 1-15.

DELIZOICOV, N.C; LOPES, A.R.L.V; ALVES, B.D. Ciências Naturais nas Séries Iniciais: características e demandas no ensino de Ciências. In: Encontro Nacional de Pesquisa em
Educação em Ciências, 5; 2005. Anais... Bauru -SP, Brasil.2005.

DELIZOICOV, D; ANGOTTI, J.A; PERNAMBUCO, M.M. Ensino de ciências: fundamentos e métodos. 2. ed. São Paulo: Cortez, 2002.

DELIZOICOV, Demétrio; ANGOTTI, José. A. Metodologia do ensino de Ciências. 2. ed. São Paulo: Cortez, 2000.

DELVAL, Juan. Introdução à prática do método clínico. Descobrindo o pensamento das crianças. Porto Alegre: Artmed, 2002.

DIAS, P.K.S; SILVA, F.G. Avalia BH Revista Pedagógica Ciências da Natureza - $1^{\text {o }}$ Ciclo, Juiz de Fora. v. 3, jan/dez. 2011. Disponível em:

$<$ http://www.avaliabh.caedufjf.net/repos itorio/diagnosticabh/pdf/AVALIABH B OLETIM VOL 1 2011.pdf> Acesso: 29 de fev.de2015.

DOMINGUEZ, C.R.C; TRIVELATO, S.L.F. Crianças pequenas no processo de significação sobre borboletas: como utilizam as linguagens? Revista Ciência. E Educação, Bauru, v. 20, n. 3, p. 687702, 2014. Disponível em: < http://www.scielo.br/pdf/ciedu/v20n3/1 516-7313-ciedu-20-03-0687.pdf $>$ Acesso em: 1 de mai. de 2015.

DORZIAT, A.A formação de professores e sua relação com a prática docente nas séries iniciais do Ensino Fundamental: depoimento de professoras-alunas. In: Encontro Nacional de Didática e Prática de 
Ensino, 12; 2004. Anais... Curitiba- PR, Brasil, 2004.p. 8216-8230.

DUCATTI-SILVA, K.C. A formação no curso de Pedagogia para o ensino de ciências nas séries iniciais. 2005 Dissertação (Mestrado em Educação, Faculdade de Filosofia e Ciências) Universidade Estadual Paulista Júlio de Mesquita Filho, Marília-SP, 2005.

FASSBINDER, T.R.C et al. Avaliação do desenvolvimento cognitivo na base de experiências piagetianas: uma produção técnica de vídeo. Revista Contexto \& Saúde, v. 8, n. 16, Jan./Jun. 2009. Disponível em: < https://www.revistas.unijui.edu.br/inde x.php/contextoesaude/article/view/1441 $>$ Acesso em: 4 de mai. de 2015.

FERRACIOLI, F. Aspectos da Construção do conhecimento e da aprendizagem na obra de Piaget. Caderno Brasileiro de Ensino de Física, v. 16, n. 2, p. 180-194, ago. 1999. Disponível em: < https://periodicos.ufsc.br/index.php/fi sica/article/view/6808 $>$ Acesso em: 12 de mar. de 2015.

FRACALANZA, H; AMARAL I.A; GOUVEIA, M.S.F. O ensino de ciências no primeiro grau. São Paulo: Atual, 1986.

FREITAS, D.S. et al. A literatura infantil no ensino de Ciências. In: Encontro Nacional de Didática e Prática de Ensino, 12; 2004. Anais... CuritibaPR, Brasil, 2004.p.719-740.
GIL, A.C. Como elaborar projetos de pesquisa. 4. ed. São Paulo: Atlas, 2009.

GOUVÊA, G; LEAL, M.C. Alfabetização científica e tecnológica e os museus de Ciência. In: GOUVÊA, G; MARANDINO, M; LEAL, M.C. (Org.). Educação e museu - a construção social do caráter educativo dos museus de ciência. Rio de Janeiro: ACCES, 2003.

LIMA, M.E.C. de C.; MAUÉS, E. Uma releitura do papel da professora das séries iniciais no desenvolvimento $\mathrm{e}$ aprendizagem de ciências das crianças. Revista Ensaio - Pesquisa em Educação em Ciências, v. 8, n.2, PP. 161-175.2006. Disponível em: < http://www.portal.fae.ufmg.br/seer/inde x.php/ensaio/article/viewArticle/115 > Acesso em: 2 de mai. de 2015.

LOPES JR., J. et al. Caracterização de práticas educativas no ensino de Ciências nas séries iniciais do ensino fundamental: elementos para implementação de propostas de intervenção. In: Encontro Nacional de Didática e Prática de Ensino, 12; 2004. Anais... Curitiba- PR, Brasil, 2004.p 3351-3365.

MENDONÇA, C.A.S ; MOREIRA, M.A. Uma revisão da literatura sobre trabalhos com mapas conceituais no ensino de ciência do pré-escolar às séries iniciais do ensino fundamental. Revista Práxis, ano IV, n. 7, Jan.2012. Disponível em: < http://web.unifoa.edu.br/praxis/numero s/07/11.pdf $>$ Acesso em: 2 de mai. de 2015. 
MENESTRINA, T.C. As experiências de Piaget aplicadas por acadêmicos de Licenciatura em matemática a estudantes do ensino fundamental. Revista Experiências em Ensino de Ciências, v.6, n.1, pp. 33-55, 2011. Disponível em: < http://www.if.ufrgs.br/eenci/artigos/Arti go ID131/v6 n1 a2011.pdf > Acesso em: 2 de mai. de 2015.

NICÁCIO, S.B.C. Relação Entre Desenvolvimento Cognitivo, Psicogênese do Conhecimento Aritmético de Multiplicação e Desempenho Escolar. 2003 Dissertação (Mestrado em Educação) Universidade Estadual de Campinas, Campinas - SP, 2003.

PIAGET, J. O nascimento da inteligência na criança. 4. ed. Rio de Janeiro: Zahar, 1982.

Le Jugement et le Raisonnement chez L Enfant. Neuchâtel: Delachaux et Nestlé, 1924. [O Raciocínio da Criança. Rio de Janeiro: Record, 1967].

A equilibração das estruturas cognitivas. Rio de Janeiro: Zahar, 1975.

RIBEIRO, E.M. Avalia BH - Rede Municipal de Educação. Centro de Políticas Públicas e Avaliação da Educação da Universidade Federal de Juiz de Fora (CAEd/UFJF). Belo Horizonte: Rona Editora, 2012. Disponível em: <http://gestaocompartilhada.pbh.gov.br/ sites/gestaocompartilhada.pbh.gov.br/fil es/biblioteca/arquivos/revistaavaliabh20 12.pdf>. Acesso em: 20 de fev. de 2015.

ROSA, D.C. Textos de divulgação científica nas Séries Iniciais: um caminho para alfabetização científicotecnolópgica de crianças. 2002. Dissertação (Mestrado em Educação) Universidade Federal de Santa Maria, Santa Maria - RS, 2002.

SANTOS, S.R.M.C; OLIVEIRA,V.B. Intervenção psicomotora lúdica na construção do pensamento operatório.Boletim Academia Paulista de Psicologia, v.29,n.1,pp.164-182,2009. Disponível em: < http://pepsic.bvsalud.org/scielo.php?pid $=$ S1415-

711X2009000100013\&script $=$ sci arttext $>$ Acesso em: 2 de mai. de 2015.

SILVA, A.F.A. Ensino e aprendizagem de Ciências nas séries iniciais: concepções de um grupo de professoras em formação. 2006. Dissertação (Mestrado em Interunidades em Ensino de Ciências) Universidade de São Paulo, São Paulo, 2006.

UNESCO BRASIL. Ensino de Ciências: o futuro em risco. 2005. $<$ Disponível em: http://unesdoc.unesco.org/images/0013/ 001399/139948por.pdf.> Acesso em: 01 mai. 2015.

VIECHENESKI, J.P; CARLETTO, M. Porque e para quê ensinar ciências para as crianças. Revista Brasileira de Ensino de Ciência e Tecnologia, v. 6, n. 2, Mai./Ago. 2013. Disponível em: < 
https://periodicos.utfpr.edu.br/rbect/arti cle/view/1638/1046 > Acesso em: 4 de mai. de 2015.

VIECHENESKI, J.P; LORENZETTI, L; CARLETTO, M. Desafios e práticas para o ensino de ciências e alfabetização científica nos anos iniciais do ensino fundamental. Revista Atos de Pesquisa em Educação, v. 7, n. 3, p. 853-876, set./dez. 2012. Disponível em: < http://proxy.furb.br/ojs/index.php/atosd epesquisa/article/view/3470/2182

Acesso em: 3 de mai. de 2015.

ZANON, D.A.V. Ensinar e aprender Ciências no ensino fundamental com atividades investigativas: enfoque no projeto $A B C$ na Educação Científica Mão na Massa. 2005. Tese (Doutorado em Educação) - Universidade Federal de São Carlos, São Carlos - SP, 2005. 